\title{
SECOND INTERNATIONAL SPECIALIZED SYMPOSIUM ON YEASTS
}

\author{
Tokyo, Japan, August 7-10, 1972 \\ Theme: Yeasts and Yeast-like Microorganisms in \\ Medical Science
}

In accordance with the resolution of the Third International Symposium on Yeasts at Delft and The Hague, 1969, the Second International Specialized Symposium on Yeasts will be held in Tokyo, Japan from August 7 to 10, 1972. This Symposium will deal mainly with the medical aspects of yeasts and yeast-like microorganisms.

\section{Program}

The following fields concerning yeasts and yeast-like microorganisms with particular reference to medical science will be covered:
A. Taxonomy
B. Morphology and Ultrastructure
C. Genetics
D. Physiology, Biophysics and Biochemistry
E. Ecology
F. Epidemiology
G. Pathogenesis
H. Clinical Aspects
I. Laboratory Diagnosis
J. Immunology
K. Chemotherapy
L. Medicinal and Industrial Application

All abstracts should be in the hands of the Organizing Committee not Iater than April 1, 1972. 